\title{
CRESCIMENTO E DESENVOLVIMENTO DE CLONES DE CAJAZEIRA CULTIVADOS NA CHAPADA DO APODI, CEARÁ ${ }^{1}$
}

\author{
FRANCISCO XAVIER DE SOUZA², JOSÉ TARCISO ALVES COSTA², \\ RAIMUNDO NONATO DE LIMA ${ }^{4}$ E JOÃO RIBEIRO CRISÓSTOMO ${ }^{2}$
}

\begin{abstract}
RESUMO -O ensaio com clones de cajazeira foi avaliado, na chapada do Apodi, em Limoeiro do Norte - CE. Utilizou-se o delineamento experimental de blocos ao acaso, em esquema fatorial (cinco copas x dois porta-enxertos), com quatro repetições e quatro plantas por parcela. As copas foram obtidas de plantas adultas produtivas das localidades de Capuan, Caucaia-CE; Curimatã, Pacajus-CE; Gereau e Ladeira Grande, Maranguape-CE e Lagoa Redonda, Fortaleza-CE e os porta-enxertos de sementes de cajazeira e de umbuzeiro. O objetivo foi caracterizar o crescimento vegetativo e a produção de frutos dos clones de cajazeira. Os clones Gereau e Lagoa Redonda foram os mais vigorosos, tiveram as maiores alturas de planta $(390 \mathrm{~cm})$ e espessuras de caule $(57 \mathrm{~cm})$. O Ladeira Grande foi o menos vigoroso, com altura $(220 \mathrm{~cm})$ e espessura de caule $(49 \mathrm{~cm})$, diferindo significativamente dos demais. O porta-enxerto de cajazeira formou caule mais espesso que o de umbuzeiro. A razão entre os perímetros de caule (enxerto e porta-enxerto) foi menor que 1,0 no porta-enxerto de cajazeira e maior no de umbuzeiro. O número de frutos por cacho variou de 8 a 76. Algumas plantas dos clones Lagoa Redonda e Gereau sobre umbuzeiro produziram de 100 a 300 cachos de frutos por planta. Os clones formam plantas de porte baixo, vigorosas, com aspectos fenotípicos e morfológicos distintos a cada clone, não alterando o padrão de crescimento do caule principal e do formato de copa; o porta-enxerto de cajazeira forma plantas com troncos mais vigorosos do que os de umbuzeiro; as razões de perímetros de caule, enxerto e porta-enxerto são maiores nas combinações com umbuzeiro, mas sem indícios de incompatibilidade; o porta-enxerto de umbuzeiro aumenta o porte, precocidade e produtividade dos clones, notadamente do Gereau e Lagoa Redonda sendo que o clone Ladeira Grande é o de menor porte.
\end{abstract}

Termos para indexação: Spondias mombin, porta-enxertos, fruticultura, enxertia, taperebá, cajá.

\section{GROWTH AND DEVELOPMENT OF CLONES HOGPLUM CULTIVED IN APODI PLATEAU, CEARÁ, BRAZIL}

\begin{abstract}
The experiment was established, at the Apodi Plateau; in Limoeiro do Norte County, State of Ceará (Brazil). A randomized block design was used with a factorial $5 \times 2$ ( 5 scions on 2 rootstocks), with 4 replicates and 4 plants per plot. Scions stem from superior plants collected in the counties of Caucaia (Capuan locality), Pacajus (Curimatã locality), Maranguape (Gereau e Ladeira Grande localities) and Fortaleza (Lagoa Redonda locality). Rootstocks were prepared from seeds of S. mombin L. and S. tuberosa Arruda. All scions and rootstocks were collected in Ceará State. The parameters assessed were the vegetative growth and fruit setting. Clones Gereau and Lagoa Redonda were the most vigorous, higher $(3.9 \mathrm{~m})$ and with bigger stem girth $(57 \mathrm{~cm})$. Ladeira Grande showed the poorest peformance in hight $(2.2 \mathrm{~m})$ and stem girth $(49 \mathrm{~cm})$ and, being statistically different from the others. As far as the root-stocks are concerned those from S. mombim were superior to $S$. tuberosa. The stem girth ratio was less than 1.0 for $S$. mombin rootstocks and higher than 1.0 for $S$. tuberosa rootstocks. The number of fruits per bunch of studied clones presented values of raged from 8 to 76. Some plants of Lagoa Redonda and Gereau clones on $S$. tuberosa yielded from 100 to 300 bunches. Final results confirmed that scions of $S$. mombin grafted on rootstocks of $S$. mombin and S. tuberosa produced combinations with the following characterists: vigorous clones with distinct phenotypic and morphological features such as low hight, uniform canopies and standardized main stem growth; S. mombin rootstocks allowed the formation of plants with more vigorous stems compared with rootstocks of $S$. tuberosa; the stem girth, graft and rootstock ratios were higher for combinations on $S$. tuberosa, but without indications of grafting incompatibility; the rootstock of $S$. tuberosa increase plant hight, productive and precocious of clones Gereau e Lagoa Redonda, and clone Ladeira Grande showed the lowest hight.
\end{abstract}

Index terms: Spondias mombin, rootstoks, fruits, grafting, yellow mombin.

\section{INTRODUÇÃO}

A família Anacardiaceae agrupa o gênero Spondias (Airy Shaw \& Forman, 1967; Mitchell \& Daly, 1998) do qual se destacam a cajazeira ( $S$. mombin L.), o umbuzeiro ( $S$. tuberosa Arruda), a cajaraneira (S. dulcis Parkinson), a cirigüeleira (S. purpurea L.) e a umbu-cajazeira (Spondias sp.). Essas espécies são exploradas extrativamente ou em pomares domésticos e não fazem parte das estatísticas oficiais, mas, mesmo assim, têm grande importância socioeconômica para as regiões Norte e Nordeste do Brasil (Souza, 1998). Seus frutos são nuculânios perfumados com mesocarpo carnoso, amarelo, de sabor agridoce, contendo carotenóides, açúcares, vitaminas A e C (Barroso et al., 1999). Os frutos da cajazeira, devido a seu característico sabor, são muito procurados para processamento de polpas, sucos, geléias, néctares e sorvetes de excelente qualidade e alto valor comercial, tornando viável a exploração agroindustrial dessa fruteira (Souza, 2000). Em face da falta de pomares comerciais, as agroindústrias ficam totalmente dependentes da produção obtida do extrativismo, que é sazonal e insuficiente para operacionalização das fábricas durante todo o ano.

No Brasil, as cajazeiras são encontradas isoladas ou agrupadas, notadamente em regiões da Amazônia e da Mata Atlântica e nas zonas mais úmidas dos Estados do Nordeste, principalmente na faixa litorânea e nas serras, e de forma espontânea ou subespontânea em matas, campos de pastagens ou pomares domésticos (SOUZA, 2000). A disseminação das sementes é feita por animais e pela água, e a multiplicação, por sementes e por estaquia. É planta típica de zonas úmidas e subúmidas, ocorre principalmente nas regiões costeiras de maior precipitação, nos limites mais úmidos do agreste e nas regiões de encostas de serra do Ceará e do Rio Grande do Norte; está presente nas caatingas do semi-árido somente quando plantada (SAMPAIO, 2002). No Ceará, ocorre com maior

\footnotetext{
1 (Trabalho 24-2006). Recebido: 09-03-2006. Aceito para publicação: 06-10-2006. 1 Artigo extraído da Tese Doutorado do primeiro autor

${ }^{2}$ Eng. Agrôn., D.Sc. Embrapa Agroindústria Tropical, CP 3761, 60 511-110, Fortaleza - CE. xavier@ cnpat.embrapa.br

${ }^{3}$ Eng. Agrôn., P.hD, Professor Titular do Departamento de Fitotecnia da Universidade Federal do Ceará. CP. 12168 CEP 60356-001 Fortaleza, CE

${ }^{4}$ Eng. Agrôn., M.Sc. Embrapa Agroindústria Tropical, CP 3761, 60 511-110, Fortaleza - CE. rlima@ cnpat.embrapa.br
} 
freqüência nas zonas litorâneas próximas à Fortaleza e nas serras de Guaramiranga, Baturité, Meruoca e Ibiapaba (SACRAMENTO \& SOUZA, 2000).

A cajazeira é uma árvore frutífera tropical lenhosa, ainda em domesticação. Tem porte alto, folhas caducas e tronco revestido por casca grossa e rugosa que esgalha e ramifica na parte terminal, o que confere um porte alto à planta. A copa é ampla, vistosa e imponente quando em fase de floração e frutificação (SOUZA \& BLEICHER, 2002). É uma espécie selvagem, sendo os fatores mais limitantes para seu cultivo as variações de formato de copa, produtividade, tamanho e sabor dos frutos (Villachica, 1996), o alto porte e a longa fase juvenil das plantas obtidas de sementes (Souza, 1998). O emprego de plantas clonadas tem sido a alternativa de superação desses problemas na maioria das fruteiras cultivadas.

$\mathrm{Na}$ Zona da Mata de Ilhéus - BA, a cajazeira propagada por sementes começa a produzir seis ou sete anos após o plantio, enquanto plantas clonadas por enxertia produzem após o terceiro ano de cultivo, apresentando altas taxas de crescimento e porte elevado, com altura média de 4,46 m (Leite et al., 2003). Em Pacajus $\mathrm{CE}$, clones de cajazeira enxertados sobre umbuzeiro também apresentaram altas taxas de crescimento, com troncos monopodias (haste única) e tendência a formar copas altas, sendo que algumas plantas produziram apenas no primeiro ano de cultivo (Souza \& Bleicher, 2002).

A propagação da cajazeira a partir de rebentos de raízes (Soares, 1988), estações de caule (Souza, 1998), estacas de caule (Souza \& Lima, 2005) e por cultura de tecidos (Medeiros et al., 2000) não se tornou viável para a formação de pomares comerciais, devido aos baixos rendimentos de produção de mudas. A propagação por garfagem, notadamente sobre porta-enxertos de outras Spondias, conforme Souza et al. (1999) e Souza (2000), tem se destacado como o método mais apropriado e eficiente, com altos índices de pega, possibilitando a formação de mudas para o plantio aos 60 dias após a enxertia.

Plantas enxertadas são combinações de genótipos que podem proporcionar características não previsíveis de crescimento e desenvolvimento diferentes das de seus componentes. A planta obtida por enxertia possui um sistema radicular do porta-enxerto e um sistema de ramos do enxerto e apresenta padrão de crescimento distinto daqueles observados, se cada uma das partes, porta-enxerto e enxerto tivesse se desenvolvido separadamente. Tais características resultam do próprio processo de enxertia, de reações de incompatibilidade ou de influências mútuas das partes envolvidas (Kester, 1976; Hartmann et al., 2002) e podem ser desejáveis para o cultivo em termos de porte, precocidade de frutificação, uniformidade produtiva e qualidade de frutificação.

Para caracterizar o crescimento vegetativo (altura de planta, perímetros dos caules do porta-enxerto e do enxerto, relação entre perímetros de caule enxerto/porta-enxerto) e produção de frutos avaliou-se um pomar com clones de cajazeira enxertados sobre portaenxertos de pé-franco de umbuzeiro e da própria cajazeira, cultivado na chapada do Apodi, em Limoeiro do Norte - CE.

\section{MATERIAL E MÉTODOS}

O pomar foi plantado em fevereiro de 2000 , em área do Instituto Frutal, localizada a $5^{\circ} 12^{\prime} 9,8^{\prime \prime} \mathrm{S}$ e $37^{\circ} 59^{\prime} 29,2^{\prime \prime} \mathrm{W}$ e altitude de $158 \mathrm{~m}$ (GPS 12), no DIJA - Distrito de irrigação Jaguaribe-Apodi, em Limoeiro do Norte - CE. O solo da área é um Cambissolo Háplico, com argila de atividade alta a fraca (EMBRAPA, 1999). Os tratamentos consistiram de combinações de cinco copas de cajazeira enxertadas sobre dois porta-enxertos (cajazeira e umbuzeiro), arranjadas no campo em delineamento de blocos ao acaso, em esquema fatorial, com quatro repetições e quatro plantas por parcela, totalizando 160 plantas na área útil e 56 na bordadura externa. Os clones-copa foram obtidos de árvores de pé-franco, sadias e produtivas com mais de 50 anos de idade, de troncos altos e esgalhados na parte terminal, das localidades

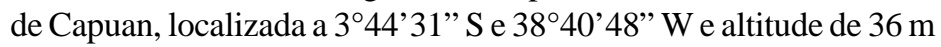
em Caucaia-CE; Curimatã, localizada a $4^{\circ} 11^{\prime} 6$ " S e $38^{\circ} 30^{\prime} 40^{\prime \prime} \mathrm{W}$ e altitude de $89 \mathrm{~m}$ em Pacajus-CE; Gereau, localizada a $3^{\circ} 56^{\prime} 3^{\prime \prime} \mathrm{S}$ e $38^{\circ} 42^{\prime} 57^{\prime \prime}$ 'W e altitude de 187 m e Ladeira Grande, localizada a $3^{\circ} 55^{\prime} 52^{\prime \prime}$ S e 38 42' $59^{\prime \prime}$ 'W e altitude de $212 \mathrm{~m}$ em Maranguape-CE; e Lagoa Redonda, localizada a 3 ${ }^{\circ} 48^{\prime} 27^{\prime}$ 'S e 38 $27^{\circ}$ ' $15^{\prime \prime}$ W e altitude de $13 \mathrm{~m} \mathrm{em}$ Fortaleza-CE. As combinações (enxerto/porta-enxerto) resultaram nos seguintes tratamentos: 1= Capuan/cajazeira; $\mathbf{2}=$ Curimatã/cajazeira; $\mathbf{3}=$ Gereau/cajazeira; 4= Ld. Grande/cajazeira; 5= Lg. Redonda/ cajazeira; $\mathbf{6}=$ Capuan/umbuzeiro; $7=$ Curimatã/umbuzeiro; $8=$ Gereau/ umbuzeiro; $9=\mathrm{Ld}$. Grande/umbuzeiro e 10=Lg. Redonda/umbuzeiro. De cada planta matriz (clone copa) foi selecionada uma única planta para retirada dos enxertos e os porta-enxertos foram obtidos de sementes de diversas plantas de umbuzeiro e de cajazeira.

As mudas dos clones foram formadas por garfagem em fenda cheia, no viveiro do Campo Experimental da Embrapa Agroindústria Tropical, em Pacajus, CE, conforme método proposto por Souza et al. (1999). O plantio das mudas foi realizado em sistema retangular, no espaçamento de $8 \times 7 \mathrm{~m}$ em área de relevo plano, medindo 126 x $96 \mathrm{~m}$ $\left(12.096 \mathrm{~m}^{2}\right)$. As covas com dimensões de $40 \times 40 \times 40 \mathrm{~cm}$, foram previamente tratadas com carbofuran a $0,05 \%$ e adubadas em fundação com $10 \mathrm{~L}$ de esterco bovino curtido, $100 \mathrm{~g}$ de calcário dolomítico (PRNT 80\%), $400 \mathrm{~g}$ de superfosfato simples (72 $\mathrm{g} \mathrm{de}_{2} \mathrm{O}_{5}$ ) e $40 \mathrm{~g}$ do micronutriente FTE BR.

Os tratos culturais consistiram de irrigação por microaspersão (apenas durante o período seco do primeiro, segundo e terceiro anos de cultivo), adubações em cobertura e fertirrigações, para estabelecimento do pomar. Realizaram-se, também, replantio, tutoramento, coroamento e capinas manuais com enxada, e controle preventivo, com repelente químico, contra formigas saúvas. Realizouse poda de formação que consistiu do corte da gema apical, em março de 2001, ou do terço superior do caule das plantas que continuavam com crescimento monopodial, em agosto de 2001, seguida da aplicação de uma pasta de oxicloreto de cobre nas superfícies cortadas.

\section{Variáveis Avaliadas}

Altura de planta (medição feita da superfície do solo até o ápice do ramo mais desenvolvido), perímetro de caule do portaenxerto e do enxerto (medição feita circundando o caule do portaenxerto e do enxerto logo abaixo e acima do ponto de enxertia), relação entre os perímetros de caule do porta-enxerto e do enxerto, e níveis de cachos de frutos por planta (número de cachos de frutos/planta, sendo os níveis $0=$ produção de nenhum cacho/planta; $1=$ produção de um a dez; 2 = produção de 11 a 50; e 3 = produção maior que 50 cachos/planta).

Essas variáveis, exceto níveis do número de cachos de frutos/ planta foram submetidas à análise de variância, utilizando-se do teste F, a 5\% de probabilidade, conforme Pimentel-Gomes (1987). Os contrastes entre as médias dos tratamentos foram testados pelo teste de Duncan (BANZATTO \& KRONKA, 1995).

Para a variável nível do número de cachos de frutos/planta, cujos dados não se ajustaram ao emprego da análise de variância e de testes não-paramétricos, realizou-se uma análise descritiva utilizando-se do recurso de tabelas cruzadas com o software SPSS, versão 13.

\section{RESULTADOS E DISCUSSÃO}

\section{Altura de Planta}

Efeitos significativos de altura de planta foram encontrados apenas para o fator copa em todas as idades (Tabela 1). Diferenças consideráveis de altura de planta são observadas entre os clones desde os 12 meses de idade, quando o Gereau teve o maior valor $(104,30 \mathrm{~cm})$, seguido pelo Lagoa Redonda $(89,28 \mathrm{~cm})$, os quais não 
TABELA 1 - Altura de planta $(\mathrm{cm})$ das copas de cajazeira e dos porta-enxertos, valores do teste F, coeficiente de variação e média geral, em cinco idades. Limoeiro do Norte - CE, 2005.

\begin{tabular}{lccccc}
\hline Copa (C) & 12 meses & 18 meses & 30 meses & 46 meses & 55 meses \\
\hline Capuan & $67,44 \mathrm{~b}$ & $67,13 \mathrm{~b}$ & $151,66 \mathrm{~b}$ & $244,48 \mathrm{~b}$ & $304,28 \mathrm{~b}$ \\
Curimatã & $56,36 \mathrm{cb}$ & $47,16 \mathrm{c}$ & $128,69 \mathrm{~b}$ & $213,79 \mathrm{c}$ & $301,14 \mathrm{~b}$ \\
Gereau & $104,30 \mathrm{a}$ & $102,28 \mathrm{a}$ & $200,03 \mathrm{a}$ & $293,44 \mathrm{a}$ & $380,59 \mathrm{a}$ \\
Ladeira Grande & $42,42 \mathrm{c}$ & $40,68 \mathrm{c}$ & $95,65 \mathrm{c}$ & $154,44 \mathrm{~d}$ & $215,93 \mathrm{c}$ \\
Lagoa Redonda & $89,28 \mathrm{a}$ & $85,69 \mathrm{a}$ & $201,34 \mathrm{a}$ & $287,20 \mathrm{a}$ & $398,13 \mathrm{a}$ \\
\hline Porta-enxerto (PE) & & & & & $309,70 \mathrm{a}$ \\
Cajazeira & $71,41 \mathrm{a}$ & $67,63 \mathrm{a}$ & $151,58 \mathrm{a}$ & $234,36 \mathrm{a}$ & $33,04 \mathrm{a}$ \\
Umbuzeiro & $71,57 \mathrm{a}$ & $69,91 \mathrm{a}$ & $160,18 \mathrm{a}$ & $248,86 \mathrm{a}$ & 3,17 \\
\hline CV (\%) & 52,77 & 50,88 & 31,90 & 24,17 & 23,95 \\
F (C) & $13,23 * *$ & $17,28 * *$ & $26,82^{* *}$ & $27,65 *$ & $25,41 * *$ \\
F (PE) & 0,01 & 0,12 & 0,99 & 1,24 & 3,21 \\
F (CxPE) & 1,14 & 2,13 & 1,96 & 1,00 & 1,74 \\
\hline Média geral & 71,49 & 68,76 & 155,85 & 241,27 & 323,20 \\
\hline
\end{tabular}

${ }^{1}$ As plantas foram podadas em março e julho de 2001.

Médias seguidas por letras iguais, na mesma coluna, não diferem entre si, pelo teste de Duncan $(\mathrm{p}<0,05)$.

* Significativo ao nível de 5\% de probabilidade e ** ao nível de $1 \%$ de probabilidade, pelo teste F.

TABELA 2 - Perímetro de caule do porta-enxerto $(\mathrm{cm})$ das copas de cajazeira e em cada porta-enxerto, valores do teste F, coeficiente de variação e média geral, em cinco idades. Limoeiro do Norte - CE, 2005.

\begin{tabular}{lccccc}
\hline Copa (C) & 12 meses & 18 meses & 30 meses & 46 meses & 55 meses \\
\hline Capuan & $9,66 \mathrm{ab}$ & $13,31 \mathrm{ab}$ & $27,56 \mathrm{a}$ & $41,14 \mathrm{ab}$ & $54,16 \mathrm{ab}$ \\
Curimatã & $8,06 \mathrm{bc}$ & $11,53 \mathrm{bc}$ & $26,47 \mathrm{ab}$ & $37,79 \mathrm{bc}$ & $49,94 \mathrm{~b}$ \\
Gereau & $11,27 \mathrm{a}$ & $15,13 \mathrm{a}$ & $29,78 \mathrm{a}$ & $44,94 \mathrm{a}$ & $55,30 \mathrm{ab}$ \\
Ladeira Grande & $7,16 \mathrm{c}$ & $10,48 \mathrm{c}$ & $23,74 \mathrm{~b}$ & $34,70 \mathrm{c}$ & $48,91 \mathrm{~b}$ \\
Lagoa Redonda & $9,10 \mathrm{bc}$ & $13,25 \mathrm{ab}$ & $28,38 \mathrm{a}$ & $41,83 \mathrm{ab}$ & $59,15 \mathrm{a}$ \\
\hline Porta-enxerto (PE) & & & & & $58,25 \mathrm{a}$ \\
Cajazeira & $9,15 \mathrm{a}$ & $13,09 \mathrm{a}$ & $30,51 \mathrm{a}$ & $44,43 \mathrm{a}$ & $47,32 \mathrm{~b}$ \\
Umbuzeiro & $8,92 \mathrm{a}$ & $12,42 \mathrm{a}$ & $23,86 \mathrm{~b}$ & $35,69 \mathrm{~b}$ & 23,73 \\
CV (\%) & 40,78 & 38,82 & 23,65 & 23,63 & 2,11 \\
F (C) & $5,52 * *$ & $4,13 * *$ & $3,92 * *$ & $4,99 * *$ & $20,39 * *$ \\
F (PE) & 0,30 & 0,79 & $43,03 * *$ & $32,66 *$ & 0,95 \\
F (CxPE) & 0,58 & 0,50 & 0,22 & 0,76 & 53,66 \\
\hline Média geral & 9,04 & 12,75 & 27,21 & 40,26 & \\
\hline
\end{tabular}

${ }^{1}$ As plantas foram podadas em março e julho de 2001.

Médias seguidas por letras iguais, na mesma coluna, não diferem entre si, pelo teste de Duncan $(\mathrm{p}<0,05)$.

* Significativo ao nível de $5 \%$ de probabilidade e ** ao nível de $1 \%$ de probabilidade, pelo teste $\mathrm{F}$.

TABELA 3 -Perímetro de caule do enxerto $(\mathrm{cm})$ das copas de cajazeira e em cada porta-enxerto, valores do teste F, coeficiente de variação e média geral, em cinco idades. Limoeiro do Norte - CE, 2005.

\begin{tabular}{|c|c|c|c|c|c|}
\hline Copa (C) & 12 meses & 18 meses $^{1}$ & 30 meses & 46 meses & 55 meses \\
\hline Capuan & $7,91 b$ & $11,25 b$ & $25,72 b$ & $38,76 b$ & $52,07 \mathrm{~b}$ \\
\hline Curimatã & $6,45 b c$ & $9,71 b c$ & $26,09 b$ & $36,59 b$ & $47,66 \mathrm{bc}$ \\
\hline Gereau & $9,90 \mathrm{a}$ & $13,63 a$ & $30,84 a$ & $43,88 \mathrm{a}$ & $60,19 a$ \\
\hline Ladeira Grande & $5,94 \mathrm{c}$ & $8,65 c$ & $22,23 c$ & $31,70 \mathrm{c}$ & $44,14 \mathrm{c}$ \\
\hline Lagoa Redonda & $7,41 \mathrm{bc}$ & $10,38 b c$ & $25,56 b$ & $37,20 \mathrm{~b}$ & $53,17 b$ \\
\hline \multicolumn{6}{|c|}{ Porta-enxerto (PE) } \\
\hline Cajazeira & $7,55 \mathrm{a}$ & $10,54 a$ & $26,85 \mathrm{a}$ & $39,82 \mathrm{a}$ & $54,71 \mathrm{a}$ \\
\hline Umbuzeiro & $7,47 \mathrm{a}$ & $10,94 a$ & $25,34 \mathrm{a}$ & $35,64 b$ & $48,14 b$ \\
\hline CV (\%) & 43,44 & 41,12 & 24,61 & 23,47 & 25,03 \\
\hline $\mathrm{F}(\mathrm{C})$ & $6,77 * *$ & $5,74 * *$ & $7,26 * *$ & $7,18 * *$ & $6,64 * *$ \\
\hline $\mathrm{F}(\mathrm{PE})$ & 0,12 & 0,29 & 2,26 & $9,04 * *$ & $10,72 * *$ \\
\hline $\mathrm{F}(\mathrm{CxPE})$ & 1,58 & 0,68 & 0,86 & 1,00 & 0,56 \\
\hline Média geral & 7,51 & 10,74 & 26,11 & 37,83 & 51,54 \\
\hline
\end{tabular}

${ }^{1}$ As plantas foram podadas em março e julho de 2001.

Médias seguidas por letras iguais, na mesma coluna, não diferem entre si, pelo teste de Duncan $(p<0,05)$.

* Significativo ao nível de $5 \%$ de probabilidade e ** ao nível de $1 \%$ de probabilidade, pelo teste $\mathrm{F}$. 
TABELA 4 - Razão entre o perímetro de caule do enxerto e do porta-enxerto das copas de cajazeira e em cada porta-enxertos, valores do teste F, coeficiente de variação e média geral, em cinco idades. Limoeiro do Norte - CE, 2005.

\begin{tabular}{lccccc}
\hline Copa (C) & 12 meses & 18 meses $^{1}$ & 30 meses & 46 meses & 55 meses \\
\hline Capuan & $0,81 \mathrm{~b}$ & $0,84 \mathrm{~b}$ & $0,94 \mathrm{c}$ & $0,95 \mathrm{ab}$ & $0,98 \mathrm{ab}$ \\
Curimatã & $0,80 \mathrm{~b}$ & $0,82 \mathrm{bc}$ & $0,99 \mathrm{~b}$ & $0,97 \mathrm{a}$ & $0,95 \mathrm{bc}$ \\
Gereau & $0,88 \mathrm{a}$ & $0,91 \mathrm{a}$ & $1,04 \mathrm{a}$ & $0,98 \mathrm{a}$ & $1,02 \mathrm{a}$ \\
Ladeira Grande & $0,83 \mathrm{~b}$ & $0,81 \mathrm{bc}$ & $0,95 \mathrm{bc}$ & $0,92 \mathrm{bc}$ & $0,91 \mathrm{c}$ \\
Lagoa Redonda & $0,80 \mathrm{~b}$ & $0,78 \mathrm{c}$ & $0,92 \mathrm{c}$ & $0,90 \mathrm{c}$ & $0,93 \mathrm{bc}$ \\
\hline Porta-enxerto (PE) & & & & & \\
Cajazeira & $0,82 \mathrm{a}$ & $0,79 \mathrm{~b}$ & $0,88 \mathrm{~b}$ & $0,89 \mathrm{~b}$ & $0,98 \mathrm{~b}$ \\
Umbuzeiro & $0,83 \mathrm{a}$ & $0,87 \mathrm{a}$ & $1,06 \mathrm{a}$ & $1,01 \mathrm{a}$ & $1,04 \mathrm{a}$ \\
\hline CV (\%) & 11,75 & 11,54 & 8,82 & 7,93 & 8,13 \\
F (C) & $3,91^{* *}$ & $8,08^{* *}$ & $11,01^{* *}$ & $7,24^{* *}$ & $6,39^{* *}$ \\
F (PE) & 0,05 & $26,97^{* *}$ & $199,31^{* *}$ & $78,33^{* *}$ & $66,84^{* *}$ \\
F (CxPE) & $3,40^{*}$ & 1,21 & $4,92^{* *}$ & 1,48 & $2,68^{*}$ \\
\hline Média geral & 0,82 & 0,83 & 0,97 & 0,95 & 0,96 \\
\hline
\end{tabular}

${ }^{1}$ As plantas foram podadas em março e julho de 2001

Médias seguidas por letras iguais, na mesma coluna, não diferem entre si, pelo teste de Duncan $(\mathrm{p}<0,05)$.

* Significativo ao nível de $5 \%$ de probabilidade e ** ao nível de $1 \%$ de probabilidade, pelo teste $\mathrm{F}$.

diferiram estatisticamente entre si. O Ladeira Grande teve a menor altura $(42,42 \mathrm{~cm})$ e os Capuan e Curimatã, valores intermediários. Aos 18 meses, as alturas foram inferiores às da idade anterior. Este fato é explicado pelas podas de formação de copa realizadas em março de 2001, quando foram retirados os ápices dos ramos principais, e, principalmente, pela poda drástica feita em agosto de 2001, quando foram removidos cerca de um terço dos ramos principais das plantas que continuavam com crescimento monopodial acrópeto. Aos 30 meses de idade, notou-se que os clones Lagoa Redonda e Gereau continuaram com as maiores alturas $(201,34$ e 200,03 cm, respectivamente), não diferindo significativamente entre si. Os clones Curimatã $(128,69 \mathrm{~cm})$ e Capuan $(151,66 \mathrm{~cm})$ tiveram alturas intermediárias e o Ladeira Grande, o menor valor $(95,65 \mathrm{~cm})$. Aos 46 meses, observou-se a mesma tendência de altura dos clones observada nas épocas anteriores. Todas as médias de altura diferiram significativamente entre si, na seguinte seqüência, em ordem decrescente dos clones: Gereau (293,44 cm), Lagoa Redonda (287,20 $\mathrm{cm})$, Capuan $(244,48 \mathrm{~cm})$, Curimatã $(213,79 \mathrm{~cm})$ e Ladeira Grande $(154,44$ $\mathrm{cm})$. Até os 55 meses, última época de observação, notou-se que os clones mantiveram a mesma ordem de altura das épocas anteriores. Os clones Lagoa Redonda (398,13 cm) e Gereau $(380,59 \mathrm{~cm})$ tiveram as maiores alturas de planta, os de Capuan $(304,28 \mathrm{~cm})$ e Curimatã $(301,14 \mathrm{~cm})$ mantiveram-se com valores intermediários e o Ladeira Grande continuou com o menor porte $(215,93 \mathrm{~cm})$.

A altura média das plantas enxertadas de cajazeira, aos 55 meses de idade, foi de $323,20 \mathrm{~cm}$, bastante inferior à de $446,00 \mathrm{~cm}$ observada por Leite et al. (2003) em árvores de 36 meses de idade, cultivadas no sul da Bahia. Esta diferença pode ter sido o resultado da não-realização de poda de formação e de variações mesológicas e como também genéticas dos clones usados.

Uma comparação mais precisa das diferenças de altura entre os clones é dificultada em virtude das podas realizadas aos 12 e 18 meses. Contudo, dos 30 aos 55 meses de idade, essas diferenças se mantiveram praticamente inalteradas. Ao final deste período, a maioria das plantas do pomar havia atingido a maturidade com a floração e a frutificação. É de se esperar que desta época em diante ocorra uma diminuição mais acentuada das taxas de crescimento, e as diferenças entre os clones permaneçam inalteradas.

\section{Perímetro de caule do porta-enxerto}

As diferenças de espessura entre hipóbio e epíbio são freqüentemente utilizadas para caracterizar o tipo de crescimento e as possíveis reações de incompatibilidade nas plantas enxertadas. Nas análises de variância, foram observadas diferenças altamente significativas para o fator copa em todas as idades, com exceção da última (55 meses). Para o fator porta-enxerto, houve significância estatística nas três últimas idades (30; 46 e 55 meses). Não houve interação estatisticamente significativa entre os fatores clones/copa $x$ porta-enxertos, indicando que os mesmos variam independentemente (Tabela 2)

Examinando-se a Tabela 2, verificam-se diferenças estatísticas nas idades de 30; 46 e 55 meses entre os porta-enxertos. O portaenxerto de cajazeira teve perímetro de caule superior ao de umbuzeiro em todas as idades. Os perímetros de caule dos porta-enxertos de cajazeira variaram de 9,15 a $58,25 \mathrm{~cm}$, e os de umbuzeiro, de 8,92 a $47,32 \mathrm{~cm}$. A ocorrência de maiores valores de perímetro de caule nos porta-enxertos de cajazeira deve-se à presença característica de casca grossa e rugosa nos troncos dessa espécie, diferentemente dos do umbuzeiro, que possuem casca fina e lisa. (Tabela 2).

Ainda na Tabela 2, observam-se diferenças significativas de perímetro de caule dos porta-enxertos para as diferentes copas em todas as idades. Aos 12;18; 30 e 46 meses de idade, o perímetro de caule dos porta-enxertos enxertados com a copa de Gereau foi maior que os enxertados com as demais copas. Aos 55 meses, o clone de Gereau $(55,30 \mathrm{~cm})$ foi superado pelo de Lagoa Redonda $(59,15 \mathrm{~cm})$, mas ambos não diferiram estatisticamente. Os porta-enxertos enxertados com a copa de Ladeira Grande sempre tiveram os menores perímetros de caule.

\section{Perímetro de caule do enxerto}

Na Tabela 3, verificam-se diferenças significativas entre os perímetros de caule do enxerto para copa em todas as idades, e para porta-enxerto apenas aos 46 e 55 meses, quando os perímetros de caule das copas enxertadas sobre a cajazeira foram maiores que os das enxertadas sobre umbuzeiro. A interação não foi significativa, indicando que os dois fatores agem independentemente. Os perímetros de caule das copas diferiram estatisticamente em todas as idades (Tabela 3).

Na Tabela 3, observa-se que o clone de Gereau teve os maiores perímetros de caule do enxerto (copa), diferindo estatisticamente das demais copas em todas as idades. Já o clone de Ladeira Grande teve os menores perímetros de caule da copa em todas as idades. Esses resultados indicam que houve maior crescimento secundário dos caules dos enxertos do clone de Gereau $(60,19 \mathrm{~cm})$ e menor dos do clone de Ladeira Grande $(44,14 \mathrm{~cm})$, que foram menos vigorosos.

Houve correspondência dos perímetros de caule do enxerto dos 18 para os 30 meses, de conformidade com o que ocorreu com o perímetro de caule dos porta-enxertos. Ressalta-se que o elevado 
aumento de perímetro de caule dos porta-enxertos e das copas, aos 30 meses de idade, foi devido à poda feita aos 18 meses, que alterou a relação sistema radicular x copa, quebrou a dominância apical e, possivelmente, desviou as reservas para o crescimento secundário em detrimento do crescimento primário.

Confrontando-se os valores de altura de planta, perímetro de caule de porta-enxerto e de enxerto, vê-se que as maiores alturas de planta correspondem aos maiores perímetros de caule, de modo que os clones de Gereau e Lagoa Redonda tiveram maiores alturas e também os maiores perímetros de caule de porta-enxerto e enxerto. $\mathrm{O}$ clone de Ladeira Grande, por sua vez, teve a menor altura e os menores perímetros de caule de porta-enxerto e enxerto.

\section{Razão perímetro do caule enxerto/porta-enxerto}

$\mathrm{Na}$ Tabela 4, verifica-se que houve diferenças altamente significativas para os fatores copa e porta-enxerto em todas as idades, exceto aos 12 meses para porta-enxerto. A interação entre esses dois fatores foi significativa aos 12; 30 e 55 meses, respectivamente. Mas, após análise dos resultados do desdobramento da interação, constatou-se que a significância deveu-se às pequenas diferenças na direção e magnitude de resposta para as diferentes copas. Por isso, analisaram-se os fatores como sendo independentes.

As razões de perímetro de caule enxerto/porta-enxerto foram mais elevadas para o porta-enxerto de umbuzeiro do que para o de cajazeira em todas as idades, a partir dos 18 meses. Aos 30; 46 e 55 meses, essas razões para o umbuzeiro foram maiores do que 1,0 , ou seja, os caules dos enxertos de cajazeira foram mais grossos do que os dos porta-enxertos de umbuzeiro (Tabela 2), formando troncos em formato de "garrafa" e "taça", respectivamente (Figura 1).

As diferenças das razões entre perímetros de caule enxerto e porta-enxerto não exerceram influências negativas no crescimento vegetativo das plantas e não caracterizaram nenhum tipo de incompatibilidade. Além do mais, a união das partes enxertadas foi aparentemente perfeita em ambos os porta-enxertos (Figura 1). A leve hipertrofia no porta-enxerto de umbuzeiro, também foi constatada por Souza \& Bleicher (2002) em clones de cajazeira com 46 meses de idade, os quais, até a presente data, continuam em pleno desenvolvimento na Estação Experimental da Embrapa Agroindústria Tropical, em Pacajus - CE.

A hipertrofia, quando muito acentuada, pode reduzir a vida útil da planta, por afetar o movimento de água, nutrientes, íons, sais minerais e fotoassimilados pelo sistema vascular, constituindo-se, em diversos casos, causas de incompatibilidade (HARTMANN et al., 2002). Segundo esses autores, a hipertrofia ou hipotrofia do enxerto está mais relacionada com uma tendência genética de crescimento do que com incompatibilidade.

\section{Floração e Produção de Frutos}

A primeira floração e produção de frutos foi reduzida, como era de se esperar e ocorreu no período de fevereiro a maio de 2003. Apenas três plantas do clone Lagoa Redonda e três do Gereau produziram inflorescências, variando de 2 a 20 panículas por árvore e alguns cachos de frutos. A segunda floração e produção ocorreu no período de novembro de 2003 a maio de 2004 (safra de 2003-2004), quando as plantas estavam no quarto ano de cultivo. Das 147 plantas avaliadas, $22(15 \%)$ produziram frutos.

Na safra de 2003-2004, verifica-se que todos os clones tiveram altas percentagens de plantas de nível zero (produção de nenhum cacho de fruto por planta), ou seja, um grande número de plantas improdutivas. Nenhum clone teve planta de nível 3 (produção maior que 50 cachos de frutos por planta). Entre os clones, a variação de plantas improdutivas foi de $66,7 \%$ a $100 \%$, tendo sido o clone Capuan o mais tardio. Os outros clones tiveram plantas produtivas na seguinte seqüência: Lagoa Redonda 33,3\%, sendo 30\% de plantas de nível 1 (produção de um a dez cachos de frutos por planta) e 3,3\% de nível 2 (produção de 11 a 50 cachos de frutos por planta); Gereau 18,8\%, somente de plantas de nível 2, Ladeira Grande 18,5\%, sendo 14,8\% plantas de nível 2 e 3,7\% de nível 1; e Curimatã 3,4\%, com plantas de nível 1 (Figura 2).

Ainda, na safra de 2003-2004, nota-se a alta percentagem de plantas improdutivas (de nível 0), tanto nos clones enxertados sobre porta-enxerto de cajazeira $(92,2 \%)$ como nos enxertados sobre umbuzeiro $(77,1 \%)$. Entre os porta-enxertos, houve variação no número de plantas produtivas. O porta-enxerto de umbuzeiro teve $22,9 \%$ de plantas produtivas, sendo $20,0 \%$ de plantas de nível 1 e $2,9 \%$ de nível 2 , enquanto o de cajazeira teve $7,8 \%$ plantas produtivas, somente de nível 1 (Figura 3).

A terceira frutificação das cajazeiras ocorreu no período de novembro de 2004 a maio de 2005 (safra de 2004-2005), em seu quinto ano de cultivo. Das 140 plantas avaliadas, 91 (65\%) frutificaram, um aumento de $314 \%$ de plantas produtivas em relação às da safra de 2003-2004. Apesar desse aumento de plantas produtivas, as plantas do pomar ainda não tinham atingido a total maturidade e a fase de plena frutificação. Pela Figura 4, constata-se que nessa safra houve produção em todos os clones. Os clones Capuan $(53,6 \%)$ e Curimatã $(44,4 \%)$ tiveram as maiores percentagens de plantas improdutivas e, assim como o Ladeira Grande, não tiveram nenhuma planta produtiva de nível 3. Os outros clones tiveram plantas produtivas na seguinte sequiência: Lagoa Redonda 96,2\%, com 29,7\% de plantas de nível 1, $29,6 \%$ de nível 2 e 37,0\% de nível 3; Gereau 64,6\%, com 22,6\% de plantas nível 1, 32,3\% de nível 2 e 9,7\% de nível 3; Ladeira Grande $62,9 \%$, com 44,4\% de plantas de nível 1 e 18,5\% de nível 2; Curimatã $55,5 \%$, com 40,7\% de plantas de nível 1 e $14,8 \%$ de nível 2; e o clone de Capuan 46,4\%, com 32,1\% de plantas de nível 1 e 14,3\% de nível

Os clones Lagoa Redonda e Gereau foram os mais produtivos, uma vez que tiveram o maior número de plantas frutificando, notadamente de nível 3, com 37,0\% e 9,7\% e as maiores médias de massa de fruto de $14,91 \mathrm{~g} \mathrm{e} 15,11 \mathrm{~g}$, respectivamente.

$\mathrm{Na}$ Figura 5, nota-se que a percentagem de plantas improdutivas (de nível 0) foi alta nos clones enxertados sobre cajazeira $(56,9 \%)$ e baixa nos enxertados sobre umbuzeiro $(11,8 \%)$. O porta-enxerto de umbuzeiro teve $88,2 \%$ de plantas produtivas, com $33,8 \%$ de plantas de nível 1, 36,8\% de nível 2 e 17,6\% de nível 3, enquanto o de cajazeira teve $43,0 \%$ de plantas produtivas, com $33,3 \%$ de plantas de nível 1, 8,3\% de nível 2 e somente 1,4\% de nível 3 .

As maiores percentagens de plantas produtivas de níveis $2 \mathrm{e}$ 3 foram de $36,8 \%$ e $17,6 \%$, respectivamente, no porta-enxerto de umbuzeiro, contra $8,3 \%$ e $1,4 \%$ na mesma ordem, sobre cajazeira, indicando uma possível influência do umbuzeiro no aumento da produtividade de frutos.

Nas fases de floração, constatou-se, em todos os clones, a ocorrência de altos índices de abscisão de flores, assim como ocorre com a mangueira e o cajueiro. No entanto, nas flores fertilizadas que se desenvolveram em frutos, praticamente não ocorre abortamento, a não ser os causados por danos mecânicos ou ataque de pragas e patógenos, parecendo ser essa característica inerente à espécie.

Os clones Lagoa Redonda e Gereau tinham plantas muito produtivas, com cerca de 100 a 300 cachos de frutos cada uma, na safra de 2004-2005 (Figura 6a). Verificou-se também uma grande variabilidade no número de frutos por cacho entre os clones, variando de 5 a 80 , sendo comum encontrar cachos com $8 ; 14 ; 25 ; 38 ; 56$ e até com 80 frutos (Figura 6b).

Claramente, as plantas do pomar experimental encontram-se em transição da fase juvenil para a fase adulta, não tendo ainda atingido o estado de plena produção. Segundo Kester (1976), a planta necessita de um certo período de tempo e de crescimento antes do início da plena floração. Portanto, nessa fase de transição, é comum observar-se um alto grau de variabilidade entre as plantas com relação ao seu desenvolvimento vegetativo e à atividade reprodutiva, não sendo possível tirar conclusões definitivas do potencial produtivo dos clones. 

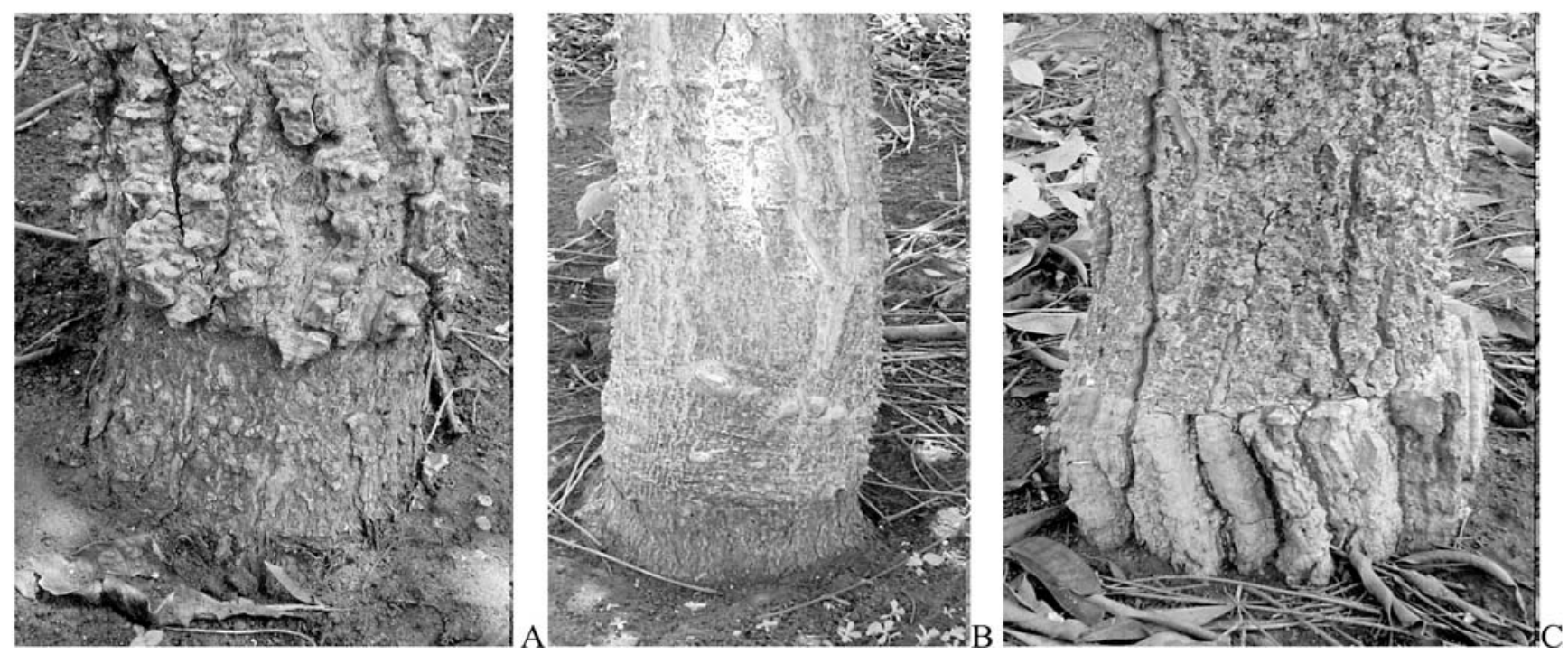

FIGURA 1 - Troncos dos porta-enxertos nos pontos de enxertia: de umbuzeiro A) em forma de "taça", B) normal e de cajazeira C) em forma de "garrafa". Limoeiro do Norte - CE, 2005.

Ciclo : $2003 / 04$

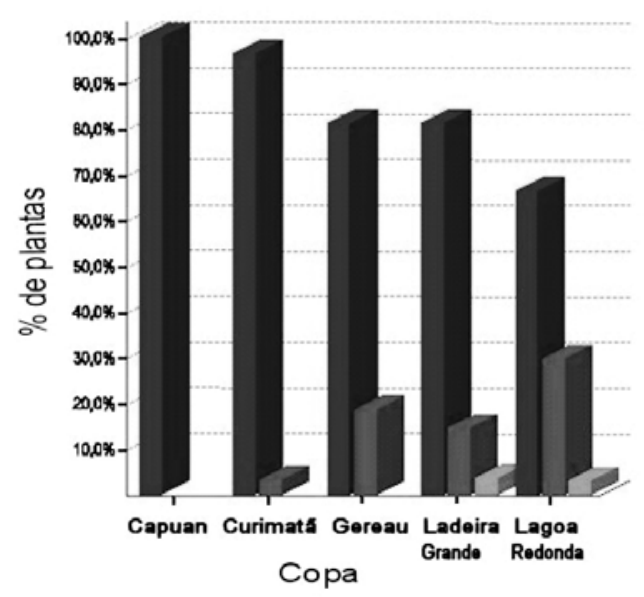

FIGURA 2 - Níveis de produção de frutos e percentagem de plantas produtivas de combinações de cinco copas de cajazeira sobre dois porta-enxertos no período de 2003-2004. Limoeiro do Norte - CE, 2005.

Ciclo : 2003/04

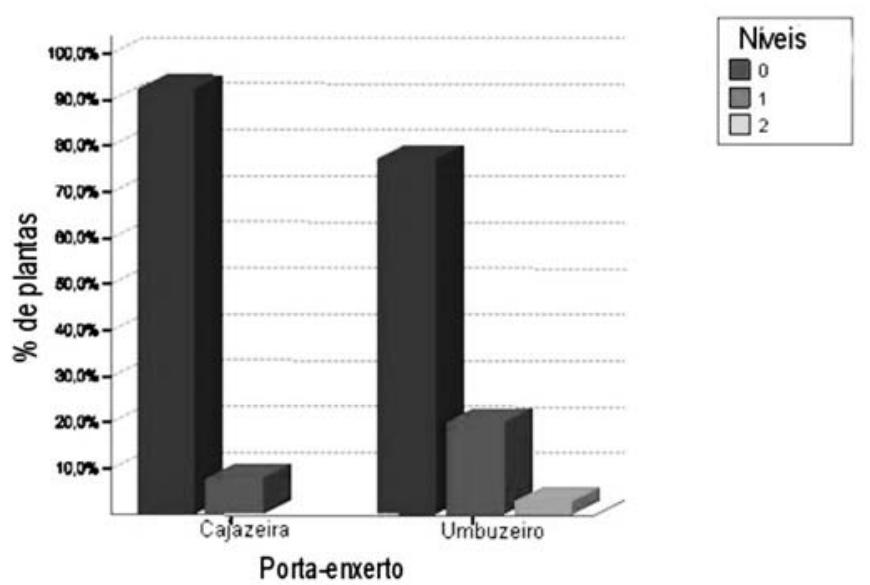

FIGURA 3 - Níveis de produção de frutos e percentagem de plantas produtivas de combinações de cinco copas de cajazeira enxertadas sobre cajazeira e umbuzeiro no período de 2003-2004. Limoeiro do Norte - CE, 2005.
Ciclo : 2004/05

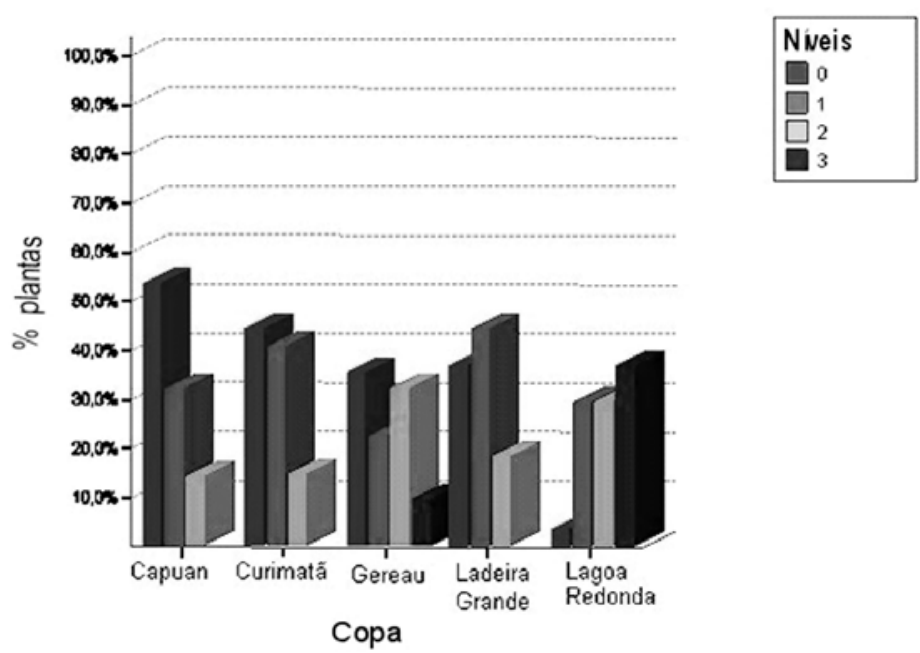

FIGURA 4 - Níveis de produção de frutos e percentagem de plantas produtivas de combinações de cinco copas de cajazeira sobre dois porta-enxertos no período de 2004-2005. Limoeiro do Norte - CE, 2005.

Ciclo : 2004/05

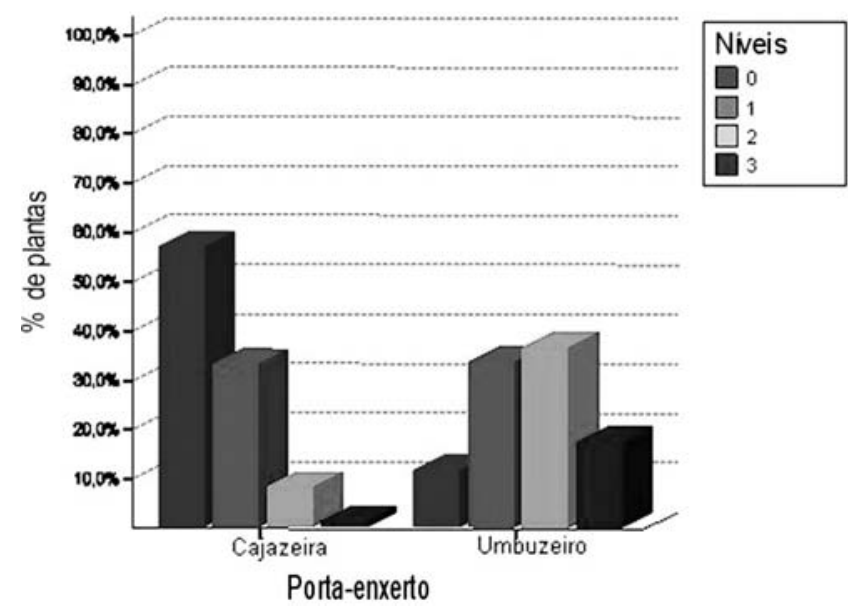

FIGURA 5 - Níveis de produção de frutos e percentagem de plantas produtivas de combinações de cinco copas de cajazeira enxertadas sobre cajazeira e umbuzeiro no período de 2004-2005. Limoeiro do Norte-CE, 2005. 


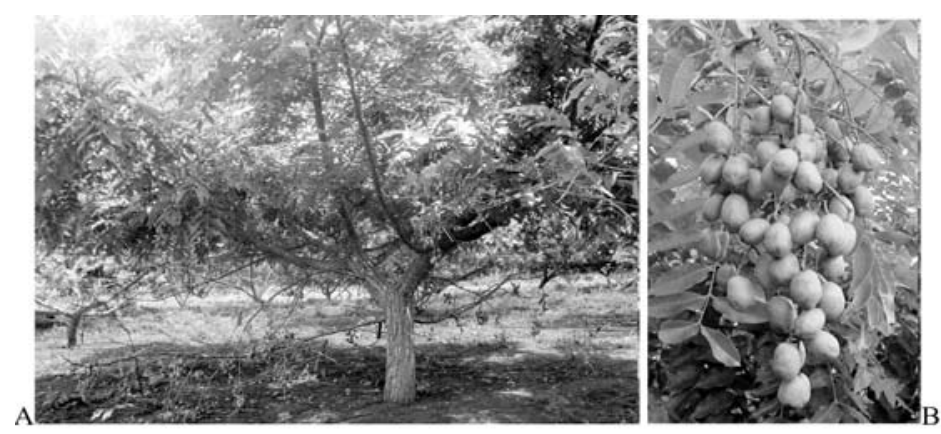

FIGURA 6 - Detalhes a) da árvore do clone Lagoa Redonda em plena produção e b) do cacho de frutos do clone Gereau na safra de 2004-2005. Limoeiro do Norte - CE, 2005.

\section{CONCLUSÕES}

As combinações de copas de cajazeira enxertadas sobre portaenxertos de umbuzeiro e de cajazeira: i) formam clones vigorosos, fixando os aspectos fenotípicos e morfológicos distintos a cada combinação, reduzindo o porte das plantas, não alterando o padrão de crescimento do caule principal e o formato de copa; ii) o portaenxerto de cajazeira forma plantas com troncos mais vigorosos do que os de umbuzeiro; iii) as razões de perímetros de caule, enxerto e porta-enxerto são maiores nas combinações com umbuzeiro, mas sem indícios de incompatibilidade; iv) o porta-enxerto de umbuzeiro aumenta o porte, a precocidade e a produtividade dos clones, notadamente do Gereau e Lagoa Redonda; v) o clone Ladeira Grande é o de menor porte.

\section{AGRADECIMENTOS}

Os autores agradecem ao $\mathrm{CNPq} / \mathrm{Padfin}$ pelo financiamento do projeto durante os dois primeiros anos e a Embrapa Agroindústria Tropical pelo apoio para a continuidade da pesquisa.

\section{REFERÊNCIAS}

AIRY SHAW, H.K.; FORMAN, L.L. The genus Spondias L. (Anacardiaceae) in tropical Asia. Kew Bulletin, London, v.21, n.1, p.1-20, 1967.

BANZATTO, D.A.; KRONKA, S.N. Experimentação agrícola. 3. ed. Jaboticabal: FUNEP, 1995. 247p.

BARROSO, G.M.; MORIM, M.P.; PEIXOTO, A.L.; ICHASO, C.L.F. Frutos e sementes: morfologia aplicada à sistemática de dicotiledôneas. Viçosa: Universidade Federal de Viçosa, 1999. 433p.

EMBRAPA. Centro Nacional de Pesquisa de Solos. Sistema brasileiro de classificação de solos. Brasília: Embrapa Produção de Informação; Rio de Janeiro: Embrapa Solos, 1999. 412p.
HARTMANN, H.T.; KESTER, D.E.; DAVIES Jr.; F.T.; GENEVE, R.L. Plant propagation: principles and practices. $6^{\text {th }}$ ed. New Jersey: Prentice Hall, 1997. 770p.

KESTER. D.E. The relationship of juvenility to plant propagation. Proceedings International Plant Propagators Society v.26, p.7184, 1976

LEITE, J.B.V.; MARTINS, A.B.G.; RAMOS, J.V. Avaliação preliminar de clones de cajazeira (Spondias mombin L.) no Sul da Bahia. In: CONGRESSO BRASILEIRO DE MELHORAMENTO DE PLANTAS, 2., 2003, Porto Seguro. Anais... Porto Seguro: SBMP, 2003. 1CD-ROM.

MEDEIROS, C.P.C. de.; CORREIA, D.; LUZ, J.M.Q. ; ROSSETTI, A.G.; BENBADIS, A.K. Cultivo in vitro de explantes nodais de cajazeira (Spondias monbim L.): etapa de desinfestação. Revista Brasileira de Fruticultura, Jaboticabal, v. 22, n. 01, p. 144-147, 2000.

MITCHELL, J.D.; DALY, D.C. The "tortoise's cajá"- a new species of Spondias (Anacardiaceae) from southweatern Amazoniza. Brittonia, New York, v.50, n.4, p.447-451, 1998.

PIMENTEL-GOMES, F. Curso de estatística experimental. 12. ed. Piracicaba: Nobel, 1987.476p.

SACRAMENTO, C.K. do.; SOUZA, F.X. de. Cajá (Spondias mombin L.). Jaboticabal: Funep, 2000. 42p. (Série Frutas Nativas, 4).

SAMPAIO, E.V.S.B. Uso das plantas da caatinga. In: SAMPAIO, E.V.S.B.; GIULIETTI, A.M.; VIRGINIO, J.; GAMARRA-ROJAS, C.F.L. Ed. Vegetação e flora da caatinga. Recife: Associação Plantas do Nordeste: Centro Nacional de Informações sobre Plantas, 2002. p.49-90. 176p.

SOARES, T.A.L. Propagação vegetativa da cajazeira (Spondias mombin L.) através de estacas de raiz. 1998. 41f. Dissertação (Mestrado) - Universidade Federal do Ceará, Fortaleza, 1998.

SOUZA, F.X., de. Spondias agroindustriais e os seus métodos de propagação. Fortaleza: EMBRAPA-CNPAT:SEBRAE-CE, 1998. 28 p. (Documentos, 27).

SOUZA, F.X. de. Efeito do porta-enxerto e do método de enxertia na formação de mudas de cajazeira (Spondias mombin L.). Revista Brasileira de Fruticultura, Jaboticabal, v.22, n.2. p.286-290, 2000.

SOUZA, F.X. de.; BLEICHER, E. Comportamento da cajazeira enxertada sobre umbuzeiro em Pacajus, CE. Revista Brasileira de Fruticultura, Jaboticabal, v.24, n.3, p.790-792. 2002.

SOUZA, F.X. de.; LIMA, R.N. Enraizamento de estacas de diferentes matrizes de cajazeira tratadas com ácido indolbutírico. Revista Ciência Agronômica, Fortaleza, v.37. n.2, p.189-194. 2005.

SOUZA, F.X. de; INNECCO, R.; ARAÚJO, C.A.T. Métodos de enxertia recomendados para a produção de mudas de cajazeira e de outras fruteíras do gênero Spondias. Fortaleza: EMBRAPA-CNPAT, 1999. 8p. (Comunicado Técnico, 37).

VILLACHICA, H.; CARVALHO, J.E.U. de.; MÜLLER, C.H.; DIAZ, S.C.; ALMANZA, M. Frutales y hortalizas promisorios de la Amazonia. Lima: Tratado de Cooperacion Amazonica/Secretaria Pro-Tempore, 1996. p.270-4. (TCA-SPT, 44). 